\title{
Hyperuricemia Predicts Residual Diuresis Decline in Peritoneal Dialysis Patients
}

\author{
Natalia Stepanova ${ }^{1 \star}$, Lyudmyla Snisar ${ }^{1}$, Larysa Lebid ${ }^{1}$
}

\begin{abstract}
${ }^{1}$ State Institution "Institute of Nephrology of the National Academy of Medical Sciences of Ukraine”, Department of Nephrology and Dialysis, UKRAINE
\end{abstract} *Corresponding Author: nmstep88@gmail.com

Citation: Stepanova N, Snisar L, Lebid L. Hyperuricemia Predicts Residual Diuresis Decline in Peritoneal Dialysis Patients. Electron J Gen Med. 2021;18(1):em270. https://doi.org/10.29333/ejgm/9297

\section{ARTICLE INFO}

Received: 9 Jun. 2020

Accepted: 26 Sep. 2020

\section{ABSTRACT}

Introduction. The effect of serum uric acid (SUA) concentration on residual urine volume in peritoneal dialysis (PD) patients has not been postulated yet. The present study aimed to investigate the effect of SUA concentration on residual diuresis in PD patients.

Methods. It was a retrospective observational study involving 175 patients who were treated with PD for at least 3 months. The primary study outcome was residual dieresis decline $<100 \mathrm{~mL} / 24 \mathrm{~h}$ represented as the time to onset of anuria.

Results. A total of 175 PD patients with the median PD vintage of 13.5 [5.0-19.7] months before the enrollment were included in the study. Among the participants, there were 79 (45.2\%) men and 96 (54.8\%) women. Hyperuricemia was found in $48 / 79(60.8 \%)$ men and $39 / 96(40.6 \%)$ women $(p=0.008)$. Residual renal function was significantly lower in the PD patients with hyperuricemia compared with the hyperuricemia-free patients. During a 22.5 [15.8-28.3] month follow-up period, 64 (42.3\%) PD patients progressed to anuria and its prevalence was significantly higher in the hyperuricemic group compared with the normouricemic group (64.3\% vs $20.4 \%$, $p$ $<0.001)$. The multivariate logistic regression analysis demonstrated that hyperuricemia was an independent risk factor associated with the development of anuria in PD patients. The additional Cox regression analysis confirmed hyperuricemia as a predictor for anuria development in the PD patients: $\mathrm{HR} 2.6(95 \% \mathrm{Cl} 1.38 ; 4.9), \mathrm{p}=0.003$.

Conclusions. Hyperuricemia is an independent risk factor for residual diuresis decline $<100 \mathrm{~mL} / 24 \mathrm{~h}$ in $\mathrm{PD}$ patients.

Keywords: peritoneal dialysis, serum uric acid, residual renal function, diuresis

\section{INTRODUCTION}

Peritoneal dialysis (PD) is now widely used as a dialysis treatment modality for advanced chronic kidney disease [1,2]. Recently, scientific and technical development advances have significantly increased the duration of PD treatment. However, the mean duration of PD treatment still does not exceed 5 years $[1,2]$. Residual diuresis (RD) has been shown to be an independent risk factor for oxidative stress aggravation, chronic inflammation, technique failure and increased mortality in PD patients [2-6].

Hyperuricemia is a well-established clinical feature in endstage renal disease patients [7-10]. It has been demonstrated that hyperuricemia plays a causal role in the development of hypertension, cardiovascular diseases, and, accordingly, it is associated with an increased rate of mortality in PD patients $[7,8,11,12]$.

The association between serum uric acid (SUA) and chronic kidney disease (CKD) progression in different populations has been well-described in previous studies [13-15]. However, the effect of SUA concentration on residual urine volume in PD patients has not yet been postulated. Therefore, the present study aimed to investigate the effect of SUA concentration on residual diuresis decline in PD patients.

\section{METHODS}

This retrospective observational study was a part of an ongoing Institute's project "The Detection of Oxalate and Uric Acid Metabolism Effect on Chronic Kidney Disease Evolution" (Domestic Trial Registration Number 0119U00002). The study protocol was reviewed and approved by the Ethics Committee of the Institute. Written informed consent was obtained from all study participants.

Inclusion criteria were: age $>18$ years, dialysis treatment for at least 3 months and a stable clinical condition. A stable clinical condition was defined as achievement and maintenance of target blood pressure levels, hydration status and peritoneal dialysis adequacy at the time of the patients' enrollment to the study. In addition, the enrolled patients did not take urate-lowering therapy. Exclusion criteria were: the presence of anuria (24-h urine volume $<100 \mathrm{~mL}$ ) before enrollment, history of systemic diseases, malignancy, acute 
inflammation processes and/or immunosuppressive treatment.

\section{Study Population}

The study population included 175 patients who started PD therapy covering the period from January 1, 2007 to April 30, 2017. All PD patients were treated with usual dwell time (4-5 hours during the daytime and 8-10 hours at night) receiving commercially available glucose-based Dianeal PD solution (Baxter Inc.) of different strengths (1.36\%, $2.27 \%)$ and Icodextrin. Dialysis prescription was guided by the target to achieve a value of $\mathrm{Kt} / \mathrm{V} \geq 1.7$ in accordance with the National Kidney Foundation Kidney Disease Outcomes Quality Initiative Clinical Practice Guidelines for Peritoneal Dialysis Adequacy [16].

\section{Data Collection}

Demographic characteristics and clinical parameters including age, gender, body mass index, ESRD causes and diabetic status were collected from the medical records of the study participants at the time of the enrollment. The index date was defined as the date of the first available SUA measurement after starting PD. The average SUA value from two consecutive measurements taken within 1-3 months period was recorded as a SUA level that determined hyperuricemia status. Then, the PD patients were followed from the index date until the time of onset of anuria or the end of the study (December 31, 2019), whichever occurred first. The data of blood creatinine $(\mathrm{Cr})$ concentration, urea (Ur), albumin, total cholesterol (TC), fasting blood glucose, hemoglobin $(\mathrm{Hb}), \mathrm{C}$-reactive protein (CRP), serum electrolytes and other routine laboratory markers were collected from the medical records of the participants at the enrollment time. All biochemical parameters were carried out using a Flexor Junior Chemistry Analyzer (Vital Scientific, Dieren, Netherlands). Hematological parameters of blood were determined using an "ABX Micros-60" (France).

Body mass index (BMI) was calculated as weight in kilograms divided by the square of the height in meters. Dialysis adequacy was determined by measuring total weekly creatinine clearance $(\mathrm{CrCl})$ (it was normalized to $1.73 \mathrm{~m}^{2}$ of body surface area) and total weekly urea clearance (Kt/V) using the Watson formula for body water [17]. Peritoneal Kt/V, plasma and renal $\mathrm{Kt} / \mathrm{V}$ were estimated separately. The dialysate/plasma creatinine ratio $(D / P)$ was calculated from the concentrations of creatinine in 24-h dialysate and plasma.

RRF was measured by the calculation of urea and creatinine clearances from a 24-h urine collection using the following standard formula:

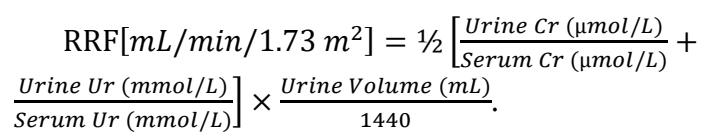

Hyperuricemia was defined as SUA concentration $\geq 420 \mu \mathrm{mol} / \mathrm{L}(7 \mathrm{mg} / \mathrm{dL}$ ) in males and $\geq 360 \mu \mathrm{mol} / \mathrm{L}(6 \mathrm{mg} / \mathrm{dL})$ in females (it was measured by automated enzymatic methods). $\mathrm{RD}$ decline was defined as 24-h urine volume of less than $100 \mathrm{~mL}$ in two consecutive measurements and determined as the time of onset of anuria. Cardiovascular comorbidities were defined as the history of angina, fatal and non-fatal myocardial infarction or stroke, heart failure or peripheral artery disease requiring hospitalization.

The primary study outcome was developing anuria during the follow-up period. Study outcomes were documented until
December 31, 2019. Switching to hemodialysis, kidney transplantation or death during the follow-up period were censored at the time happened.

\section{Statistical Analysis}

The statistical analysis and all graphs were performed using MedCalc (Belgium). The average means (M), the standard deviations (SD) or the median (Me) and the interquartile ranges [Q25 - Q75] were calculated according to the data distribution. For the statistical analysis, we used the Student's t-test (parametric data) and the Mann-Whitney U-test (nonparametric data). Categorical variables were expressed as proportions, and, the Chi-Square tests were used to compare 2 groups.

The Kaplan-Meier analysis was used to evaluate the differences in the time of onset of anuria according to SUA levels measured at the index date; the curves were compared using the log-rank test. Univariate logistic regression analysis was used to select the significant factors associated with the study outcome. Then, to control for the confounding factors, all statistically significant variables from the univariate analysis were included in the final multivariate logistic regression model. The strength of the association between RD and predictors was expressed as odds ratio (OR) and 95\% confidence interval $(\mathrm{Cl})$.

Robustness of the logistic regression model was further tested using the multivariate Cox proportional hazard model which included hyperuricemia status, age, gender, diabetes, cardiovascular comorbidities, PD-related peritonitis history and daily peritoneal ultrafiltration as covariates. The hazard ratio (HR) and 95\% confidence interval $(\mathrm{Cl})$ were calculated. The predictive value of the model was determined using a loglikelihood ratio $X^{2}$ statistic.

\section{Data Availability}

The datasets generated and analyzed during the current study are available from the corresponding author on reasonable request.

\section{RESULTS}

\section{Patient Characteristics}

A total of 175 PD patients were included in the present study. The median follow-up period was 22.5 [15.8-30.9] months. Among the patients, there were 79 (45.2\%) men and $96(54.8 \%)$ women $(p=0.07)$. Hyperuricemia was found in $48 / 79$ $(60.8 \%)$ men and $39 / 96(40.6 \%)$ women $(p=0.008)$. The characteristics of the PD participants stratified into the groups according to hyperuricemia status and the index date are shown in Table 1.

As presented in Table 1, there were more men and diabetics among the hyperuricemic patients compared with the normouricemic patients. These patients were older and had a lower level of GFR, but, they demonstrated higher body mass index, blood pressure, serum C-reactive protein, triglycerides and phosphate levels compared with the normouricemic patients. In addition, we observed a significant proportion of the PD patients with hyperuricemia who had PDrelated peritonitis history. And, therefore, they had significantly lower daily urine volume and dialysis adequacy compared with the patients without hyperuricemia. However, 
Table 1. The characteristics of the study participants according to hyperuricemia status

\begin{tabular}{|c|c|c|c|c|}
\hline Clinical parameters & $\begin{array}{l}\text { All patients } \\
(n=175)\end{array}$ & $\begin{array}{l}\text { Hyperuricemic } \\
\text { Group }(n=87)\end{array}$ & $\begin{array}{c}\text { Normouricemic } \\
\text { Group }(n=88)\end{array}$ & p-value \\
\hline \multicolumn{5}{|l|}{ Clinical parameters } \\
\hline Male gender, $\mathrm{n}(\%)$ & $79(45.2 \%)$ & $48(55.2 \%)$ & $31(35.2 \%)$ & 0.002 \\
\hline Age, years & $51[38-64]$ & $65[38-66]$ & $49.5[38-59]$ & 0.01 \\
\hline \multicolumn{5}{|l|}{ ESRD course, $\mathrm{n}(\%)$} \\
\hline - $\quad$ Diabetes & $57(32.6 \%)$ & $35(39.7 \%)$ & $22(25 \%)$ & 0.04 \\
\hline - $\quad$ Arterial hypertension & $41(23.4 \%)$ & $23(26.4 \%)$ & $18(20.4 \%)$ & 0.35 \\
\hline - Glomerulonephritis & $39(22.3 \%)$ & $18(20.7 \%)$ & $21(23.8 \%)$ & 0.62 \\
\hline - $\quad$ Other & $38(21.7 \%)$ & $11(12.6 \%)$ & $27(30.7 \%)$ & 0.003 \\
\hline PD vintage at the enrollment time, months & $13.5[5.0-19.7]$ & $13.5[7.5-22.4]$ & $17.0[8.5-21.2]$ & 0.74 \\
\hline Time on PD at the end of observational period, months & $37.5[32-49]$ & $37.0[14-51]$ & $35.5[28-53.5]$ & 0.33 \\
\hline CVD history, $\mathrm{n}(\%)$ & $38(21.7 \%)$ & $23(26.4 \%)$ & $15(17.1 \%)$ & 0.13 \\
\hline $\mathrm{RRF}\left(\mathrm{mL} / \mathrm{min} / 1.73 \mathrm{~m}^{2}\right)$ & $5.1[4.2-6.0]$ & $4.0[3.1-5.0]$ & $5.2[4.0-7.0]$ & $<0.001$ \\
\hline RD declaine $<100 \mathrm{~mL} / 24 \mathrm{~h}$ during the follow-up period, $\mathrm{n}(\%)$ & $64(42.3 \%)$ & $56(64.3 \%)$ & $18(20.4 \%)$ & $<0.001$ \\
\hline Urine volume at the end of the observational period, $\mathrm{mL} / 24 \mathrm{~h}$ & $456[50-550]$ & $250[50-550]$ & $350[300-700]$ & 0.005 \\
\hline $\mathrm{BMI}, \mathrm{kg} / \mathrm{m}^{2}$ & $25.4[21.1-29.1]$ & $25.2[23-33.3]$ & $23.7[20.9-28]$ & 0.003 \\
\hline $\mathrm{SUA}, \mu \mathrm{mol} / \mathrm{L}$ & $300[272-328]$ & $402[379-545]$ & $288[262-316]$ & $<0.001$ \\
\hline Serum albumin, $\mathrm{g} / \mathrm{L}$ & $36.5[34.4-40.8]$ & $36.1[32.8-39.8]$ & $36.6[34.4-40.9]$ & 0.36 \\
\hline CRP, mg/L & $9.7[4.3-17.2]$ & $11.5[8.0-21]$ & $8.8[6.7-17.2]$ & 0.04 \\
\hline Systolic blood pressure, $\mathrm{mm} \mathrm{Hg}$ & $128.4 \pm 14.2$ & $137 \pm 10.2$ & $122.3 \pm 14.8$ & $<0.001$ \\
\hline Diastolic blood pressure, $\mathrm{mm} \mathrm{Hg}$ & $78 \pm 12.4$ & $85 \pm 11.2$ & $73 \pm 13.2$ & $<0.001$ \\
\hline $\mathrm{Hb}, \mathrm{g} / \mathrm{L}$ & $101[92-109]$ & 97 [92-109] & $111[101-121]$ & 0.12 \\
\hline Glucose, $\mathrm{mmol} / \mathrm{L}$ & $5.6[5.08-7.6]$ & $5.6[5.04-11.8]$ & $5.3[5.08-7.6]$ & 0.61 \\
\hline Total cholesterol, mmol/L & $5.6[5.2-6.4]$ & $5.9[4.5-6.6]$ & $5.4[5.07-6.6]$ & 0.71 \\
\hline Triglycerides, $\mathrm{mmol} / \mathrm{L}$ & $1.4[1.1-2.288]$ & $2.8[0.95-3.38]$ & $1.28[0.96-2.13]$ & 0.009 \\
\hline Calcium, mmol/L & $2.34[2.2-2.37]$ & $2.29[2.12-2.37]$ & $2.33[2.21-2.37]$ & 0.74 \\
\hline Phosphorus, mmol/L & $1.9[1.57-2.2]$ & $2.4[2.2-2.8]$ & $1.7[0.9-2.2]$ & $<0.001$ \\
\hline iPTH, ng/L & $300.4[63.4-337]$ & $249[45-631]$ & 206 [63.4-249] & 0.48 \\
\hline \multicolumn{5}{|l|}{ Peritoneal dialysis parameters } \\
\hline PD-related peritonitis history, $\mathrm{n}(\%)$ & $64(36.5 \%)$ & $43(49.4 \%)$ & $21(23.8 \%)$ & 0.0005 \\
\hline Daily peritoneal ultrafiltration, $\mathrm{mL}$ & 900 [600-1909] & $1100[1000-1500]$ & $700[400-1600]$ & 0.01 \\
\hline 4-hour D/P creatinine ratio & $0.75[0.68-0.82]$ & $0.65[0.63-0.7]$ & $0.79[0.7-0.85]$ & $<0.001$ \\
\hline Icodextrin, n (\%) & $38(21.7 \%)$ & $27(31 \%)$ & $11(12.5 \%)$ & 0.003 \\
\hline Renal weekly Kt/V & $0.09[0.03-0.51]$ & $0.04[0.02-0.07]$ & $0.15[0.1-0.3]$ & $<0.001$ \\
\hline Plasma weekly Kt/V & $1.8[1.39-1.9]$ & $1.88[1.5-1.9]$ & $1.92[1.3-2.3]$ & 0.23 \\
\hline Total Kt/V & $2.09[1.72-2.3]$ & $1.9[1.7-2.0]$ & $2.05[1.9-2.5]$ & 0.01 \\
\hline $\mathrm{CrCl}, \mathrm{L} /$ week $/ 1.73 \mathrm{~m}^{2}$ & $48.6[41.9-56.3]$ & $48.2[45.1-64.3]$ & $49.1[41.6-54.5]$ & 0.54 \\
\hline \multicolumn{5}{|l|}{ Medications, $\mathbf{n}(\%)$} \\
\hline ACE inhibitors / RAAS blockers & $134(76.6 \%)$ & $69(79.3 \%)$ & $65(73.8 \%)$ & 0.93 \\
\hline Erythropoietins & $111(63.4 \%)$ & $66(75.8 \%)$ & $45(51.1 \%)$ & $<0.001$ \\
\hline Diuretics & $73(41.7 \%)$ & $30(34.5 \%)$ & $43(48.8 \%)$ & 0.06 \\
\hline Lipid-lowering therapy & $44(25.1 \%)$ & $21(24.1 \%)$ & $23(26.1 \%)$ & 0.79 \\
\hline
\end{tabular}

The values are expressed as mean \pm standard deviation $(\mathrm{M} \pm \mathrm{SD}$ ) or as the median and interquartile range (Me [Q25-Q75]). The values are compared between the groups using the Chi-square test, the Student's t-test and the Mann-Whitney $\mathrm{U}$ test as appropriate.

Abbreviations: ACE, angiotensin-converting enzyme; BMI, body mass index; $\mathrm{CrCl}$, creatinine clearance; CRP, C-Reactive Protein; D/P creatinine ratio, dialysate/plasma creatinine ratio; eGFR, estimated glomerular filtration rate; Hb, hemoglobin; iPTH, intact parathyroid hormone; RAAS, renin-angiotensin-aldosterone system; RD, residual diuresis; SUA, serum uric acid; total Kt/V, total weekly Kt/Vurea.

a high daily peritoneal ultrafiltration volume was associated with greater patient numbers in this group of Icodextrine users. There was no difference in PD vintage, cardiovascular comorbidities, hemoglobin, blood glucose and calcium concentrations between the groups. Nevertheless, the most common use of erythropoietins was observed in the PD patients with hyperuricemia.

\section{Hyperuricemia and the Risk of RD Decline $<100 \mathrm{~mL} / 24 \mathrm{~h}$}

RRF was significantly lower in the PD patients with hyperuricemia compared with the PD patients without hyperuricemia (see Table 1). During the follow-up period, 64 (42.3\%) patients from a total of 175 PD patients progressed to anuria. The prevalence of anuria was significantly higher in the hyperuricemic group compared with the normouricemic group $(64.3 \%$ vs $20.4 \%, p<0.001)$. The median time of the development of anuria was $37(95 \% \mathrm{Cl} 14 ; 61)$ months in the hyperuricemic group and $44(95 \% \mathrm{Cl} 36 ; 85)$ months in the nonhyperuricemic group (Log-rank test $p=0.0003$ ).

Univariate logistic regression analysis was performed to identify the risk factors associated with RD decline $<100 \mathrm{~mL} / 24 \mathrm{~h}$ in the PD patients. The analysis indicated that the factors such as age $>60$ years, diabetic status, hyperuricemia, daily peritoneal ultrafiltration rate> $1000 \mathrm{~mL}$, hyperphosphatemia and PD-related peritonitis history were associated with the risk of anuria. The factors identified as significant in the univariate logistic regression analysis were further included in the multivariate logistic regression analysis. It showed that hyperuricemia remained an independent risk factor associated with the development of anuria in the PD patients (Table 2).

We additionally performed the Cox regression analysis to confirm robustness of our primary findings. After adjusting for demographic characteristics, comorbidities and statistically significant co-factors obtained in the multivariate logistic 
Table 2. The predictive factors associated with anuria in the PD patients in the univariate and multivariate logistic regression analysis

\begin{tabular}{|c|c|c|c|c|c|c|}
\hline Factors & Unadjusted OR & $95 \% \mathrm{Cl}$ & p-value & Adjusted OR & $95 \% \mathrm{Cl}$ & p-value \\
\hline Age over 60 years & 1.15 & $1.02 ; 1.25$ & 0.03 & 1.04 & $0.97 ; 1.08$ & 0.07 \\
\hline Male gender & 1.34 & $0.89 ; 1.42$ & 0.36 & & & \\
\hline Diabetic status & 1.17 & $1.02 ; 1.28$ & 0.001 & 1.6 & $0.93 ; 2.1$ & 0.28 \\
\hline CV comorbidities & 1.46 & $0.67 ; 1.54$ & 0.84 & & & \\
\hline $\mathrm{BMI}, \mathrm{kg} / \mathrm{m}^{2}$ & 1.08 & $0.78 ; 1.22$ & 0.73 & & & \\
\hline Hyperuricemia & 1.21 & $1.08 ; 1.42$ & 0.0001 & 1.13 & $1.04 ; 1.28$ & 0.0001 \\
\hline Serum albumin, g/L & 1.28 & $0.93 ; 1.63$ & 0.24 & & & \\
\hline $\mathrm{CRP}, \mathrm{mg} / \mathrm{L}$ & 1.1 & $0.99 ; 1.2$ & 0.06 & & & \\
\hline Systolic blood pressure, $\mathrm{mm} \mathrm{Hg}$ & 1.03 & $0.78 ; 1.06$ & 0.75 & & & \\
\hline Diastolic blood pressure, $\mathrm{mm} \mathrm{Hg}$ & 1.04 & $0.98 ; 1.06$ & 0.26 & & & \\
\hline $\mathrm{Hb}, \mathrm{g} / \mathrm{L}$ & 0.98 & $0.95 ; 1.02$ & 0.43 & & & \\
\hline Total cholesterol, $\mathrm{mmol} / \mathrm{L}$ & 0.77 & $0.51 ; 1.03$ & 0.62 & & & \\
\hline Triglycerides, $\mathrm{mmol} / \mathrm{L}$ & 1.07 & $0.66 ; 1.47$ & 0.87 & & & \\
\hline Calcium, mmol/L & 0.69 & $0.28 ; 1.6$ & 0.39 & & & \\
\hline Hyperphosphatemia & 1.28 & $1.05 ; 1.4$ & 0.001 & 1.0 & $0.99 ; 1.01$ & 0.20 \\
\hline Daily peritoneal ultrafiltration> $1000 \mathrm{~mL}$ & 1.18 & $1.07 ; 1.28$ & 0.04 & 1.98 & $1.2 ; 3.2$ & 0.006 \\
\hline PD-peritonitis history & 1.36 & $1.2 ; 3.36$ & 0.0001 & 1.6 & $1.13 ; 2.1$ & 0.0001 \\
\hline iPTH, ng/L & 0.99 & $0.98 ; 1.0$ & 0.13 & & & \\
\hline Total Kt/V & 1.23 & $0.66 ; 2.27$ & 0.51 & & & \\
\hline $\mathrm{CrCl}, \mathrm{L} /$ week $/ 1.73 \mathrm{~m}^{2}$ & 0.98 & $0.95 ; 1.01$ & 0.12 & & & \\
\hline
\end{tabular}

Abbreviations: BMI, body mass index; $\mathrm{Cl}$, confidence interval; $\mathrm{CrCl}$, creatinine clearance; CRP, C-Reactive Protein; $\mathrm{Hb}$, hemoglobin; iPTH, intact parathyroid hormone; $\mathrm{OR}$, odds ratio total Kt/V, total weekly Kt/Vurea.

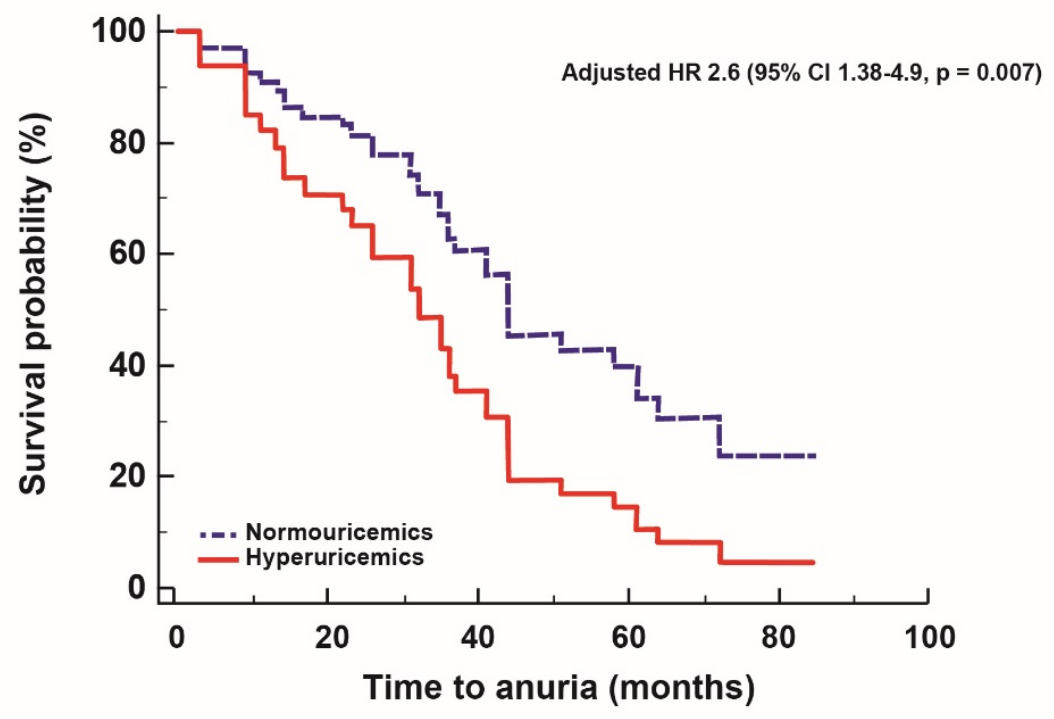

Figure 1. The time of the development of anuria dichotomized according to SUA levels in the PD patients (the Cox proportional hazards regression model)

regression model (PD-related peritonitis history and daily peritoneal ultrafiltration), hyperuricemia remained a significant predictor for the development of anuria in the PD patients (HR 2.6, 95\% Cl 1.38; 4.9, $\mathrm{X}^{2}=7.1, \mathrm{p}=0.007$ ) (Figure 1).

\section{DISCUSSION}

The negative effect of hyperuricemia on treatment outcomes in CKD patients has been demonstrated in previous studies [13-15]. The mechanisms associated with the effect of SUA include endothelial dysfunction, increased oxidative stress, platelet activation, vascular smooth muscle cells proliferation and proinflammatory activity [18]. However, in reviewing the literature, very little data was found on the role of SUA in PD patients. Moreover, a large volume of published studies has mainly focused on the association between SUA and patient survival in PD patients $[7,11,12]$. It is also worth noting that only a few studies have investigated the effect of hyperuricemia on dialysis technique failure [8] and RRF decline $[9,10]$.

The term $R R F$ is generally understood to mean the residual capacity of the kidneys to eliminate water and uremic toxins $[5,19]$. It plays a significant role in maintaining fluid balance and, accordingly, blood pressure, phosphorus control, nutrition and toxins removal $[4,5,19,20]$. However, an optimal method for measuring RRF has not yet been established. The above-mentioned reports on the association between SUA and RRF in PD patients have mainly paid close attention to the ability of the kidney to eliminate uremic toxins using estimated RRF $[9,10]$. Nevertheless, RRF loss as the time of the 
development of anuria is demonstrated in the only research [21].

In the present study, we used both methods for measuring RRF. However, to test the hypothesis whether hyperuricemia could predict RD decline, we focused on the time of the development of anuria. The main finding of our study was the strong association between hyperuricemia and RD decline $<100$ $\mathrm{mL} / 24 \mathrm{~h}$ in the PD cohort. We demonstrated a 2.6-fold increased risk of anuria and a 1.2-fold more rapid period to its development in the PD patients with hyperuricemia compared with the PD patients without hyperuricemia. Moreover, a significantly decreased RRF and renal urea clearance (renal $\mathrm{Kt} / \mathrm{V}$ ) were observed in the hyperuricemic PD patients compared with the nonhyperuricemic PD patients.

In their studies, Chiehlun Yang et al. [21] and Jung Tak Park et al. [10] have reported approximately the same prevalence of hyperuricemia in PD patients (32.1\% and $32.8 \%$, respectively). We observed a significantly higher proportion of the hyperuricemic patients (49.7\%) in the cohort of our PD patients compared with the PD patients in the studies mentioned above. There are several possible explanations for this difference: the longest follow-up period of 37.5 months, a large number of diabetics and lack of urate-lowering therapy. Nevertheless, our findings are in agreement with the above mentioned studies which showed the association between a high level of SUA and RRF loss.

Not surprisingly, we found that hyperuricemia was more commonly diagnosed compared with other CKD causes in the PD patients with diabetes. Diabetes, as well as hypertension, has been recognized as a risk of GFR decline in CKD patients [13-15,20,22]. In agreement with our result, the presence of diabetes in predicting RRF decline in PD patients has been also demonstrated in previous studies [9,10,21].

Several mechanisms could explain the negative effect of hyperuricemia on RD in PD patients. First, it has been demonstrated that the number of peritonitis episodes are associated with RRF reduction [5,19,23]. Considering the fact that peritoneal clearance dominates in SUA balance and peritonitis is a significant risk factor for structural and functional alterations in the peritoneal membrane in PD patients, an increased risk of RD decline might be observed in patients with hyperuricemia [23,24]. Second, it has been postulated that a high SUA level induces systemic and intraperitoneal inflammation [15,18,25]. In turn, chronic inflammation is also associated with low RRF $[4,19,26]$. Our result indirectly confirmed the presence of chronic inflammation associated with an increased level of serum Creactive protein in hyperuricemic patients. Third, rapid decline of RRF could be associated with malnutrition or metabolic disorders in hyperuricemic PD patients $[3,6,27,28]$. There were significant differences in body mass indexes, phosphorous and triglyceride levels between the groups in this study.

Finally, our study has some important limitations. First, bearing in mind a retrospective design of our study with relatively small sample size, causality could not be established through our findings. Second, we evaluated only the baseline effect of SUA concentration on RD decline. As SUA concentration was a time-varying parameter, it could lead to SUA misclassification and biased estimation. Third, it is unfortunate that although the potential effects of ACEinhibitors, diuretics, phosphate binders and other medications on a SUA level were demonstrated in previous studies, we did not take them into account in our research. Therefore, it did not allow us to determine the effect of these parameters on the obtained results.

Notwithstanding these limitations, the following conclusions can be drawn from the present study: 1) hyperuricemia is an independent risk factor for RD decline and anuria in PD patients; 2) SUA concentration should be closely monitored and taken into account during the strategies planning oriented to preserve RRF in PD patients. However, further studies with a larger sample size are needed to confirm our research findings.

Author contributions: All authors have sufficiently contributed to the study, and agreed with the results and conclusions.

Funding: No funding source is reported for this study.

Declaration of interest: No conflict of interest is declared by authors.

Statement of Ethics: The study was carried out in accordance with the Declaration of Helsinki. It was the framework of the Institute's research work: "The Detection of the Oxalate and Uric Acid Metabolism Effect on Chronic Kidney Disease Evolution" (Domestic Trial Registration Number 0119U00002). The study protocol was reviewed and approved by the Ethics Committee of the Institute. Writing informed consent was obtained from all study participants.

\section{REFERENCES}

1. Li PK, Chow KM, Van de Luijtgaarden MW, et al. Changes in the worldwide epidemiology of peritoneal dialysis. Nat Rev Nephrol 2017;13(2):90-103. https://doi.org/10.1038/ nrneph.2016.181 PMid:28029154

2. Stepanova N, Korol L, Burdeyna O. Oxidative Stress in Peritoneal Dialysis Patients: Association with the Dialysis Adequacy and Technique Survival. Indian J Nephrol 2019;29(5):309-16. https://doi.org/10.4103/ijn.IJN_242_18 PMid:31571736 PMCid:PMC6755929

3. Shymova AU, Shifris IM, Korol LV, Dudar IO. Nutritional Status and Indicators of Oxidative Stress among End-Stage Renal Disease Patients Treated with Continuous Ambulatory Peritoneal Dialysis. Prensa Med Argent 2020;106(2):178. Available at: https://www.scholars literature.com/article_pdf/4/scientific_4_314_3101202006 3553.pdf

4. Curran SP, Bargman JM. The importance of residual renal function in peritoneal dialysis. Dial Transplant 2011;40(8):349-55. https://doi.org/10.1002/dat.20597

5. Li T, Wilcox C, S, Lipkowitz M, S, Gordon-Cappitelli J, Dragoi S. Rationale and Strategies for Preserving Residual Kidney Function in Dialysis Patients. Am J Nephrol 2019;50:411-21. https://doi.org/10.1159/000503805 PMid:31630148

6. Stepanova N, Burdeyna O. Association between Dyslipidemia and Peritoneal Dialysis Technique Survival. Open Access Maced J Med Sci. 2019;7(15):2467-73. https://doi.org/10.3889/oamjms.2019.664 PMid:31666849 PMCid:PMC6814482

7. Feng $S$, Jiang L, Shi $Y$, et al. Uric acid levels and all-cause mortality in peritoneal dialysis patients. Kidney Blood Press Res 2013;37(2-3):181-9. https://doi.org/10.1159/ 000350143 PMid:23736777

8. Hsieh YP, Chang CC, Kor CT, Yang Y, Wen YK, Chiu PF, Lin CC. Relationship between uric acid and technique failure in patients on continuous ambulatory peritoneal dialysis: a long-term observational cohort study. BMJ Open 2017;7(4):e010816. https://doi.org/10.1136/bmjopen-2015010816 PMid:28389481 PMCid:PMC5541200 
9. Hsieh YP, Yang Y, Chang CC, et al. U-shaped relationship between uric acid and residual renal function decline in continuous ambulatory peritoneal dialysis patients. Nephrology (Carlton) 2017;22(6):427-435. https://doi.org/ 10.1111/nep.12613 PMid:26370323

10. Park JT, Kim DK, Chang TI, et al. Uric acid is associated with the rate of residual renal function decline in peritoneal dialysis patients. Nephrol Dial Transplant 2009;24(11):3520-5. https://doi.org/10.1093/ndt/gfp272 PMid:19491381

11. Xia X, Zhao C, Peng FF, et al. Serum uric acid predicts cardiovascular mortality in male peritoneal dialysis patients with diabetes. Nutr Metab Cardiovasc Dis 2016;26(1):20-6. https://doi.org/10.1016/j.numecd.2015. 10.011 PMid:26712272

12. Stepanova N, Burdeyna O, Snisar L. Hyperuricemia is associated with cardiovascular events and all-cause mortality in peritoneal dialysis patients. Nephrol Dial Transplant, 2019;34(1):i242. https://doi.org/10.1093/ndt/ gfz106.FP587

13. Kaewput W, Thongprayoon C, Rangsin R, Ruangkanchanasetr P, Bathini T, Mao MA, Cheungpasitporn W. Association between serum uric acid and chronic kidney disease in patients with hypertension: A multicenter nationwide cross-sectional study. J Evid Based Med 2019;12(4):235-42. https://doi.org/10.1111/ jebm.12364 PMid:31482688

14. Kubo S, Nishida Y, Kubota Y, et al. Higher serum uric acid level is inversely associated with renal function assessed by cystatin $C$ in a Japanese general population without chronic kidney disease: the KOBE study. BMC Nephrol 2019;20(1):117. https://doi.org/10.1186/s12882-019-1291-4 PMid:30940115 PMCid:PMC6446294

15. Mun KH, Yu GI, Choi BY, Kim MK, Shin MH, Shin DH. Effect of uric acid on the development of chronic kidney disease: The Korean multi-rural communities cohort study. J Prev Med Public Health 2018;51(5):248-56. https://doi.org/ 10.3961/jpmph.18.112 PMid:30286597 PMCid:PMC6182271

16. National Kidney Foundation. KDOQI Clinical Practice Guidelines and Clinical Practice Recommendations for 2006 Updates: Hemodialysis Adequacy, Peritoneal Dialysis Adequacy and Vascular Access. Am J Kidney Dis 2006;48:S1S322. https://doi.org/10.1053/j.ajkd.2006.04.013 PMid: 16813985

17. Ronco C. Adequacy of peritoneal dialysis is more than Kt/V. Nephrol Dial Transplant 1997;12(1):68-73.

18. Filiopoulos V, Hadjiyannakos D, Vlassopoulos D. New insights into uric acid effects on the progression and prognosis of chronic kidney disease. Ren Fail 2012;34(4):510-20. https://doi.org/10.3109/0886022X.2011. 653753 PMid:22260409
19. Liu X, Dai C. Advances in Understanding and Management of Residual Renal Function in Patients with Chronic Kidney Disease. Kidney Dis 2016;2:187-96. https://doi.org/10.1159/ 000449029 PMid:28232935 PMCid:PMC5260570

20. Demikhov O, Dehtyarova I, Rud O, et al. Arterial hypertension prevention as an actual medical and social problem. Bangladesh J Med Sci 2020;19(4):722-9. https://doi.org/10.3329/bjms.v19i4.46632

21. Yang C, Ma X, Zhao W, et al. longitudinal analysis of the relationship between serum uric acid and residual renal function loss in peritoneal dialysis patients. Ren Fail 2020;42(1):447-54. https://doi.org/10.1080/0886022X.2020. 1761387 PMid:32401146 PMCid:PMC7269070

22. Chernatska O, Demikhova N. Improvement of treatment in persons with arterial hypertension and type 2 diabetes mellitus. Georgian Med News 2018;(284):47-51. Available at: https://pubmed.ncbi.nlm.nih.gov/30618388/ PMid: 30618388

23. Szeto CC, Li PK. Peritoneal Dialysis-Associated Peritonitis. Clin J Am Soc Nephrol 20195;14(7):1100-5. https://doi.org/ 10.2215/CJN.14631218 PMid:31068338 PMCid:PMC6625612

24. Xiao X, Ye H, Yi C, et al. Roles of peritoneal clearance and residual kidney removal in control of uric acid in patients on peritoneal dialysis. BMC Nephrol 2020;21(1):148. https://doi.org/10.1186/s12882-020-01800-1 PMid:32334567 PMCid:PMC7183606

25. Stepanova N, Burdeyna O, Driianska V. Uric acid induces intraperitoneal inflammation in peritoneal dialysis patients. Nephrol Dial Transplant 2019;34(1):i238. https://doi.org/10.1093/ndt/gfz106.FP575

26. Chung SH, Heimbürger $O$, Stenvinkel $P$, Qureshi AR, Lindholm B. Association between residual renal function, inflammation and patient survival in new peritoneal dialysis patients. Nephrol Dial Transplant 2003;18(3):590-7. https://doi.org/10.1093/ndt/18.3.590 PMid:12584284

27. Chen HY, Kao TW, Huang JW, Tsai TJ, Wu KD. Association between dyslipidemia and residual renal function in patients on chronic peritoneal dialysis. Clin Nephrol 2008;70(3):233-9. https://doi.org/10.5414/cnp70233 PMid: 18793565

28. Burdeyna O, Stepanova N, Driyanska V. The association of dyslipidemia with intraperitoneal inflammation and peritoneal dialysis technique survival. Nephrol Dial Transplant 2018;33(1):i519. https://doi.org/10.1093/ndt/ gfy 104. SP506 